\title{
Intellectual Co-operation and International Science
}

A JOINT meeting of the Executive Committee of the International Council of Scientific Unions and of the Scientific Experts Committee of the International Organization of Intellectual Co-operation was held on July $9-10$, at the International Institute of Intellectual Co-operation, in Paris.

Representing the Executive Committee of the Council were: Prof. C. Fabry, chairman of the Council ; Prof. H. R. Kruyt, vice-president; Prof. D. B. Němec; Prof. F. J. M. Stratton, general secretary of the Council; E. Esclangon, representing the International Union of Astronomy ; Jean Gérard, representing the International Union of Chemistry; General Perrier and Brigadier H. St. J. L. Winterbotham, representing the International Union of Geodesy and Geophysics; General Bourgeois and E. J. Voute, representing the International Union of Geography; Profs. Abraham and A. Cotton, representing the International Union of Physics; and Dr. M. J. Sirks, representing the International Union of Biological Sciences. The Committee of Scientific Experts included: Prof. Cabrera, chairman of the Committee and professor of theoretical physics at the University of Madrid; Prof. Bialobrzeski, professor of theoretical physics in the University of Warsaw ; Prof. F. A. E. Crew, director of the Institute of Gienetics at the University of Edinburgh; Prof. P. Langevin, professor of experimental physics in the Collège de France; Prof. Ch. Maurain, dean of the Faculty of Sciences of the University of Paris ; Prof. Harry M. Miller, professor of zoology in Saint Louis University ; Prof. M. Plancherel, professor of mathematics in the Polytechnic Federal School of Zurich; Prof. A. A. J. de Sigmond, professor of agricultural chemistry in the Palatin Joseph University of Technical and Economical Sciences, Budapest; and Prof. E. Späth, rector of the University of Vienna.

This meeting is the result of several years negotiations between the International Council of Scientific Unions and the International Organization of Intellectual Co-operation, the outcome of which was the approval by the assemblies of the two organizations of the draft agreement prepared by a joint committee of representatives of the Council of Scientific Unions and of the International Committee on Intellectual Co-operation.

The agreement lays down in detail the manner in which the two institutions are to collaborate. The
International Council of Scientific Unions will henceforward act as the advisory body to the Intel. lectual Co-operation Organization on questions of a scientific character, while the latter will be consulted by the Council on all international matters concerning the organization of scientific work. The executive organs of the Intellectual Co-operation Organization will provide the secretariat for the committees to be appointed by the Council, the president of which will ex officio attend plenary meetings of the Committee on Intellectual Co-operation at which the sciences are discussed; a representative of the Intellectual Co-operation Organization will take part in the meetings of the Executive Committee of the Council.

One of the aims of the meeting of July 9-10 was the signing of this agreement by the presidents of the two organizations, Prof. Gilbert Murray and Prof. C. Fabry. It also dealt with a number of other questions, among which are: the analysis of the seientific programme of the Organization of Intellectual Co-operation, that is, co-ordination in the matter of seientific research (financial aid, collaboration with the scientific unions for the preparation of small co-ordinating committees, publication of reports on the progress made in each branch of science); scientific bibliographies (transcription of the titles and the names of authors of scientific works written in a language that does not use Roman characters. and compilation of a bibliography of scientific works published in such languages); 'scientific conversations' the first of which will deal with "the general consequences of deep alterations that have taken place in physics concerning the principles of the explanation of the natural phenomena", etc. . . .

The Committee has also studied the programme and methods of the International Council of Scientific Unions and examined several new proposals received by the Organization of Intellectual Co-operation, among which are the publication of old scientific manuscripts and the question of the co-ordination of work in the study of physical constants.

It is necessary to emphasize the importance of the signing of the agreement by the presidents of the two organizations. It marks the beginning of a practical collaboration removing all possibility of overlapping. and having as a result the development of a definite programme.

\section{New Chemistry Laboratories at Birmingham}

$\mathrm{T}$ HE new A. E. Hills Laboratories, which form a most valuable extension of the Department of Chemistry in the University of Birmingham, were formally opened by the donor (Mr. A. E. Hills) on July 7. The pro-chancellor (Mr. Walter Barrow) expressed the gratitude of the University to $\mathrm{Mr}$. Hills for his generosity in giving $£ 50,000$ to build the laboratories, as well as a further gift of $£ 25,000$ for postgraduate scholarships. Benefactions by Birmingham donors have provided a further $£ 7,700$ for equipment (including $£ 4,200$ from Cadbury Bros. and $£ 2,000$ from W. Canning and Co.)
The opening address was given by Sir Frederick Gowland Hopkins, who remarked that every encouragement given to chemistry increases the possibility of discoveries of universal value. The thoughts of physicists and that of chemists, which have been separate, are coming nearer together, and the help which chemistry has given to physics in the past is to-day being handsomely repaid; though there is still an inherent distinction between the modes of thought of the chemist and physicist which is of mutual advantage in their collabora. tion. 
Chemistry is also becoming more serviceable to medicine and all the biological sciences. The psychiatrist is now coming to the chemist for help. Many forms of mental disorder appear to arise from disturbances of metabolism which are revealed by chemical studies, and there is hope that methods of treatment may be found to correct the errors so discovered. If only some forms of insanity can be cured, it would be at least a partial solution of one of the most painful human problems. "Extending this idea, may we not believe that even the psychologist will have to pay attention to chemistry? So intimately interwoven are the activities of mind and body that no one can deny that the psychology of the individual is greatly affected by the hormonic balance which is part of his physical constitution; and hormones owe their specific influence in the body to particular aspects of their molecular structure". Chemistry in fact is ubiquitous, though it required the Great War to make Great Britain realize the truth of Disraeli's dictum that the prosperity of the chemical industry is the best index of the prosperity of the country as a whole.

The distinction between pure and applied science is becoming less real, and it is probable that never before has organic chemistry shown more possibility of continued development. How remarkable in kind the development of organic chemistry has been in its apparently static time. The product of a pictorial, or even artistic rather than mathematical type of intellect, the evolution of the idea of molecular structure was something new and distinct, and the verification by modern physical methods of the conclusions reached is indeed remarkable. Organic chemistry in approaching physics is becoming more dynamic and more subtle.

Biochemistry is a borderland subject (not a hybrid, because it is certainly not infertile), and borderland workers usually find work not found by the cultivators of either of the contiguous regions. Intellectual trust and sympathy between two departments may be very fertile. Biochemistry is the study of chemical dynamics as exhibited in life, and requires a knowledge of the physical properties and molecular structure of the substances which play an essential part in the constitution of living systems. Its special endeavour must be to follow so far as possible the function and fate of each significant constituent amid the multitudinous reactions which underlie the manifestations of life, and to explore the mechanisms which control those reactions. For this work, biochemistry is developing its own technique, and its progress though difficult is real. While immersed in problems so different in kind, it is almost impossible for the specialized biochemist to acquire the knowledge and experience, or the mode of thought and intuitions of the accomplished organic chemist, in determining molecular structure and in the difficult art of synthesis. Even the best biochemist must remain an amateur in organic chemistry. There never was a case in which progress could be better secured by a wise division of labour. Recently organic chemists have been examining the structure of natural products with marked success.

Sir Frederick concluded with a eulogy of the work of the Birmingham University School of Chemistry, referring in particular to the synthesis of vitamin $\mathrm{C}$, the commercial manufacture of which means that no case of scurvy need in future remain uncured.

\section{Standardization of Physical Units}

$I^{N}$ a paper by Lyman J. Briggs, director of the National Bureau of Standards at Washington, which appeared in the January issue of the Journal of the Franklin Institute, some of the present-day problems in connexion with securing international uniformity in standards are discussed.

The British inch, derived directly from the imperial yard, is about four parts in a million shorter than the United States unit. But if we use the conversion factor so that one inch equals $25 \cdot 4$ millimetres exactly, then the new value of the inch would fall midway between the British and the United States inch. The Bureau of Standards has definitely proposed that this be done. The change would not affect industry in the slightest because it falls well within the tolerances in industrial measurements. This conversion factor, one inch equals $25.4 \mathrm{~mm}$., has recently been adopted for industrial purposes by standardizing groups in fifteen countries including both England and the United States.

In the field of electricity, the tools of measurement now depend on national standardizing laboratories. The maintenance of units is made possible on a world-wide basis by the rise of the great national standardizing laboratories, especially in Germany, Great Britain and the United States. The revision of the units is under way at the present time. But as the present units are more than sufficiently accurate for industrial use, the changes made will only affect laboratories making very precise measurements. The change will become effective on January 1, 1940. The present 'international' units of the ampere, ohm and volt will be respectively $0.9999,1 \cdot 0005$ and 1.0004 of the new (absolute) ampere, ohm and volt respectively.

The present standards for use in photometry are either flame standards or carbon filament lamps giving light of a yellowish colour, and there is no general agreement as to a method regarding a method of passing over to lamps giving 'whiter' light. The German-speaking countries also never accepted the old 'international candle' but use their own unit, the Hefner, which is only nine tenths of it. Now that the Bureau of Standards has determined the be. haviour of the normal eye in terms of 'factors of luminosity' which have been internationally agreed, a basis has been fixed for measuring lights of any colour provided we have some kind of standard as a starting point. We have still to agree upon the photometric scale for the brightness of the primary standard. The Bureau of Standards has recently suggested that the old 'international candle' be abandoned and that a slightly different unit be fixed by taking the round value of 60 candles per sq. $\mathrm{cm}$., instead of the old value of $58 \cdot 9$, as the brightness of the blackbody radiator at the platinum point. 